\title{
EVOLUTIONARY RELATIONSHIPS OF ATOPOSAURID CROCODYLIFORMS AND EVIDENCE FOR ALLOPATRIC SPECIATION DRIVING THEIR HIGH DIVERSITY IN THE LATE JURASSIC OF EUROPE

\section{INTRODUCTION}

Atoposaurids comprise a clade of small-bodied terrestrial and semi-aquatic crocodyliforms. They were an important component of Late Jurassic and Early Cretaceous European ecosystems, with less common occurrences extending their known stratigraphic range from the Middle Jurassic to the end Cretaceous (Fig. 1). Despite a range of recent discoveries, there is currently little taxonomic consensus for atoposaurid inter-relationships. Most of these genera are multispecific, with Theriosuchus having five currently accepted species spanning some 80 million years. Several additional putative atoposaurid taxa, if valid, would extend their range into the Late Jurassic of Asia, and the Early Cretaceous of North America and Africa.

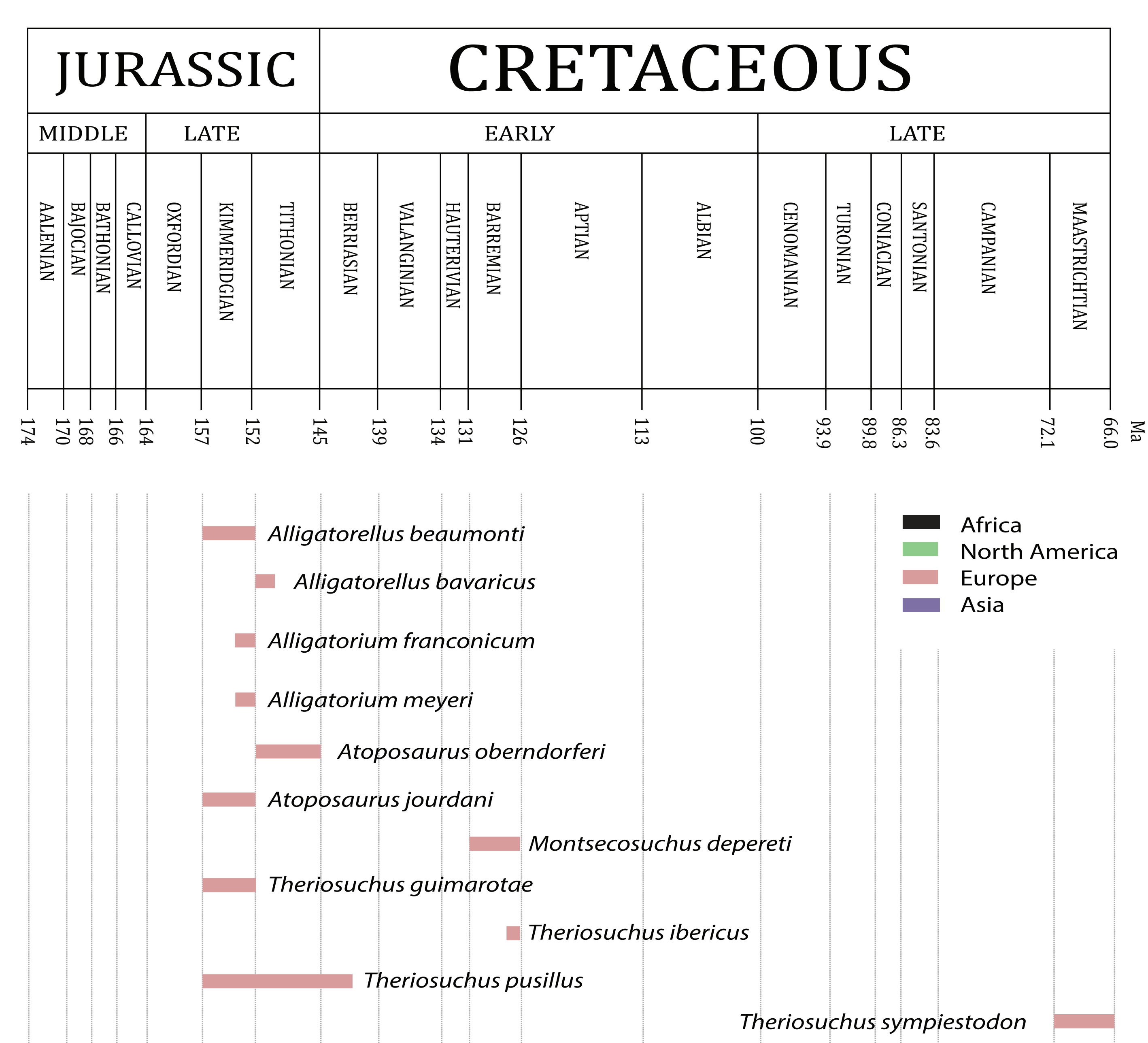

- Skye specimen

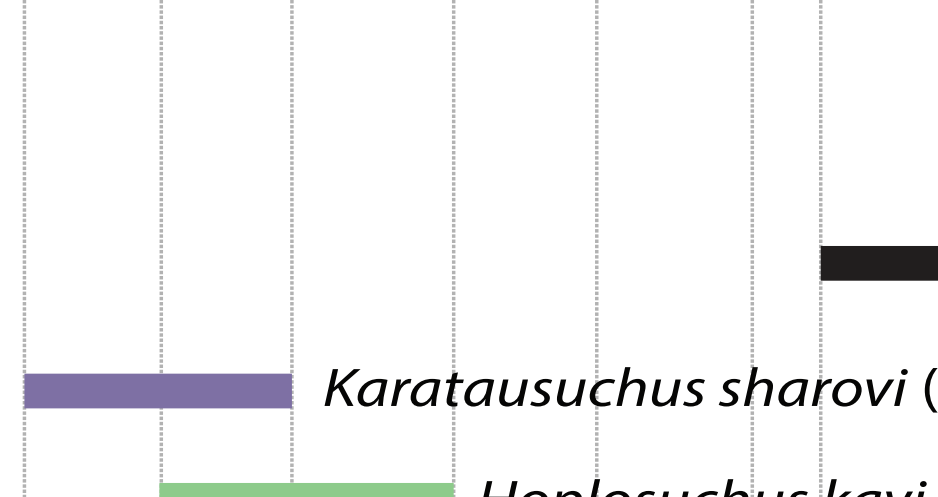

Hoplosuchus kayi (?)

Figure 1. Stratigraphic and geographic distribution of known and putative atoposaurid species. Modified from [1].

\section{PHYLOGENETIC ANALYSIS}

A new matrix was built comprising 7 outgroup and 13 ingroup taxa, and 352 characters. This dataset was analysed in TNT v. 1.1, resulting in 3 MPTs with a length of 654 steps. The strict consensus tree was timescaled in the $R$ package strap using the 'equal' method (Fig. 5).

\section{RESULTS}

All Theriosuchus species form a clade including Wannchampsus, recently named as a paralligatorid [2]. This suggests that either Wannchampsus should be referred to Theriosuchus, or there is greater diversity within this clade. Irrespective, this provides evidence for an Early Cretaceous atoposaurid radiation into both North America and Asia. Both Alligatorellus and Atoposaurus species group together, strengthening our arguments for their validity as separate genera.

\section{CONCLUSIONS AND FUTURE RESEARCH}

These results confirm the monophyly of Atoposauridae, and suggest that a taxonomic revision of Theriosuchus is required. Future research will require comparison with other small neosuchians, including bernissartiids, and incorporation of other putative atoposaurids such as Brillanceausuchus and Karatausuchus. Inclusion of these taxa should help to confirm the position of Atoposauridae within Neosuchia and stabilise the within-group relationships.

\section{LATE JURASSIC EUROPEAN DIVERSITY}

Taxonomic revision of western European atoposaurids leads us to recognise the existence of three closely related and sympatric genera in the Late Jurassic French and German basins, including the newly re-ranked species Alligatorellus bavaricus ([1] Fig. 2). This provides evidence for allopatric speciation, possibly driven by fluctuating highstand sea levels (Fig. 3). A principal components analysis of key morphometric characteristics, combined with unique anatomical features and primary indicators of ontogenetic age, shows that these genera cannot be conclusively demonstrated to be part of the same growth series, as previously suggested (Fig. 4).
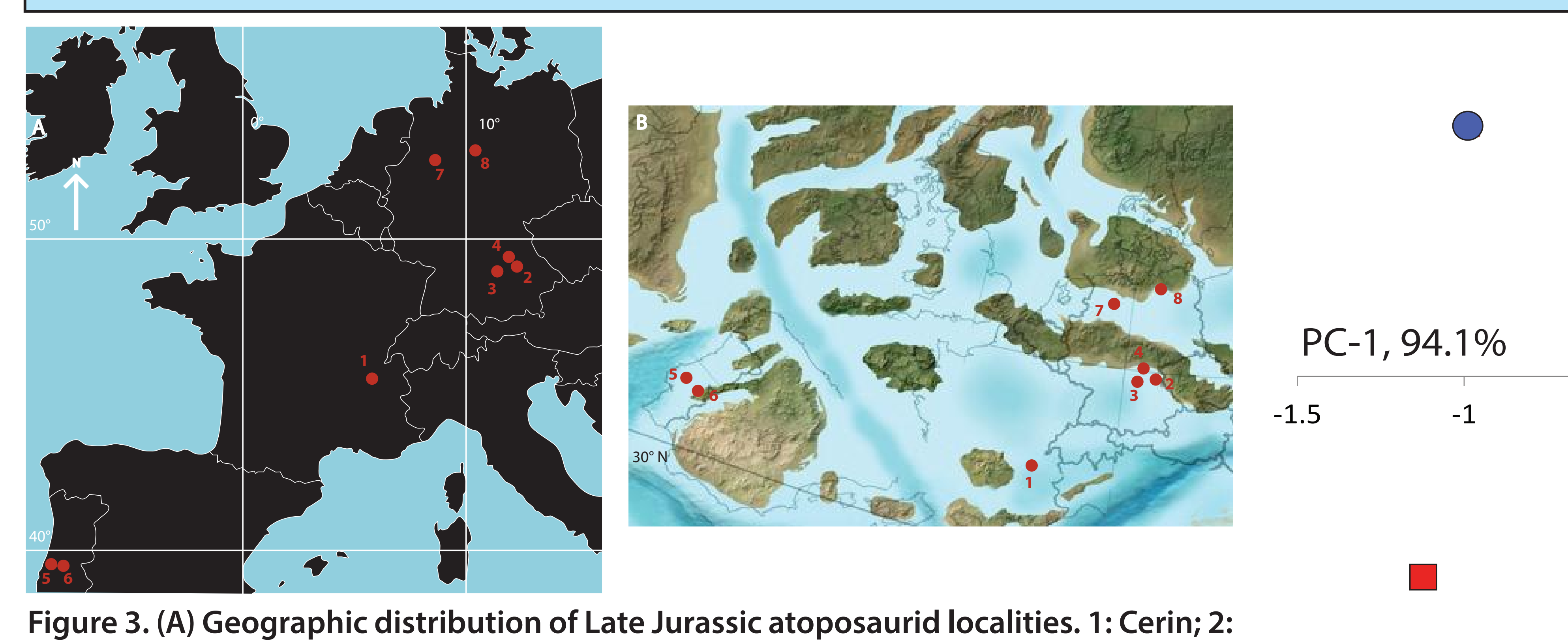

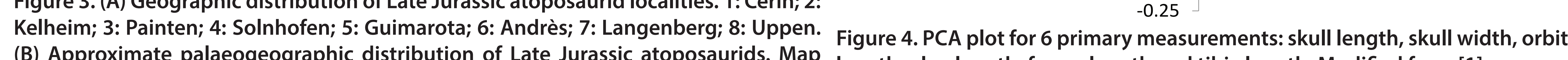
(B) Approximate palaeogeographic distribution of Late Jurassic atoposaurids. Map length, ulna length, femur length and tibia length. Modified from [1].
reconstruction from Ron Blakey, Colorado Plateau Geosystems, Arizona USA reconstruction from Ron Blakey, Colorado P
(http://cpgeosystems.com/paleomaps.html). [1]

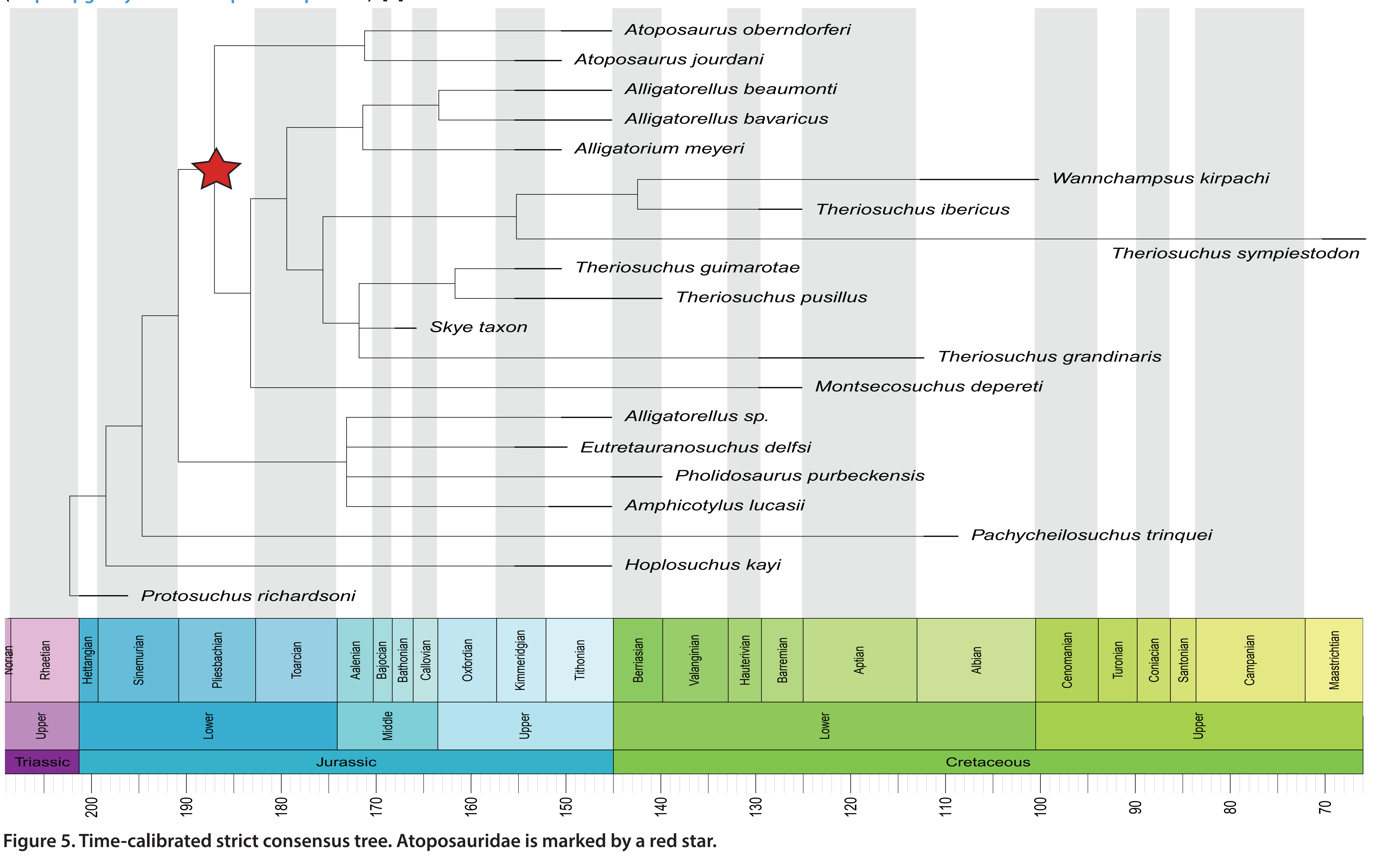

1] Tennant, J. P. and Mannion, P. D. (2014) Revision of the ate Jurassic crocodyliform Alligatorellus, and evidence for llopatric speciation driving high diversity in western European atoposaurids, PeerJ, 2 e599

] Adams, T. L. (2014) Small crocodyliform from the Lower retaceous (Late Aptian) of central Texas and its Journal of Paleontology, 88, 1031-1049 